\title{
Response to letter to the editor, "Neuroradiologic Manifestations of COVID-19: What the Emergency Radiologist Needs to Know"
}

\author{
Michael F. Goldberg ${ }^{1}$ (D) Morton F. Goldberg ${ }^{2}$ \\ Received: 9 November 2020 / Accepted: 16 November 2020 / Published online: 7 January 2021 \\ (C) American Society of Emergency Radiology 2021, corrected publication 2021
}

To whom it may concern:

We thank Josef Finsterer et al. for their "Letter to the Editor" in response to our review article, "Neuroradiologic Manifestations of COVID-19: What the Emergency Radiologist Needs to Know" [1].

Although our review articles emphasized the most common neuroradiologic manifestations of COVID-19 that we would expect an emergency radiologist to encounter, we appreciate Josef Finsterer et al.'s effort to highlight the less common, but interesting, diagnoses that can also be encountered in this devastating infection.

\section{Compliance with Ethical Standards}

Conflict of interest No conflicts of interest.

\section{Reference}

1. Goldberg MF, Goldberg MF (2020) Neuroradiologic manifestations of COVID-19: what the emergency radiologist needs to know. Emerg Radiol 27:737-745. https://doi.org/10.1007/s10140-02001840-y

Publisher's note Springer Nature remains neutral with regard to jurisdictional claims in published maps and institutional affiliations.

Presentation at Meeting N/A

Michael F. Goldberg

Michael.goldberg@ahn.org

1 Division of Neuroradiology, Imaging Institute, Allegheny Health Network, 320 E. North Ave, Pittsburgh, PA 15212, USA

2 Johns Hopkins Medical Institutions, Baltimore, USA 